\title{
Distinguishing Neuroimaging Features in Patients Presenting with Visual Hallucinations
}

\author{
(D)T.T. Winton-Brown, (D)A. Ting, (D) Rocellin, (DD. Velakoulis, and (D) F. Gaillard
}

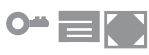

\begin{abstract}
SUMMARY: Visual hallucinations are relatively uncommon presentations in medical and psychiatric clinics, where they are generally regarded as a marker of possible underlying "organic" brain disease. Thus, patients with visual hallucinations are often referred for imaging of the brain. This article presents a pragmatic approach for the radiologist reviewing such imaging. Because conditions that can present with visual hallucinations are legion, a familiarity with the features of the hallucinations themselves, which can serve as clues to the underlying cause, can be helpful in interpreting such cases. We consider the nature of visual hallucinations and the mechanisms underlying their formation. We then provide a framework to guide the search for their cause, first in terms of focal lesions along the visual pathway and then global conditions affecting $>1$ region.
\end{abstract}

ABBREVIATIONS: CJD = Creutzfeldt-Jakob disease; $\mathrm{VH}=$ visual hallucination

$\mathbf{T}$ he presentation of visual hallucinations (VHs) to general medical and psychiatric clinics often triggers a search for underlying "organic" brain disease and a referral for imaging of the brain, first with CT and then MR imaging. If the findings are interpreted as normal, patients who in actuality have underlying organic disease can have delays in diagnosis and prolonged inappropriate management. Therefore, it behooves the reporting radiologist to be familiar with visual hallucinations and the possible causes thereof.

The organic causes of VHs represent a veritable Augean stable of pathologies, ranging widely in etiology and location within the brain (Table 1). Although in some instances, a focal defined lesion can lead to VHs (eg, an occipital lobe cavernoma), pathology can also affect large or multiple areas simultaneously (eg, posterior cortical atrophy or Creutzfeldt-Jakob disease [CJD]). When one reviews scans of patients with VHs, it is important to assess not only each part of the visual system but also more diffuse, global, or multiregional pathologies. We have pragmatically divided this article into focal and global causes based simply on localization

From the Departments of Neuropsychiatry (T.T.W.-B., R.M., D.V.) and Radiology (A.T., F.G.), Royal Melbourne Hospital, Parkville, Victoria, Australia; and Melbourne Neuropsychiatry Centre (D.V.), National Neuroscience Facility, Carlton, Victoria, Australia.

Please address correspondence to Frank Gaillard, Royal Melbourne Hospital, Grattan St, Parkville, 3050 Victoria, Australia; e-mail: Frank.gaillard@gmail.com

- Indicates open access to non-subscribers at www.ajnr.org

= Indicates article with supplemental on-line table.

Indicates article with supplemental on-line photo.

http://dx.doi.org/10.3174/ajnr.A4636 rather than on a clear understanding of the pathophysiology of VHs. We briefly consider the nature of hallucinations and clues in the clinical context on the request form. We then consider mechanisms underlying the formation of VHs to guide the search for their cause. We suggest looking first at focal lesions along the visual pathway and then conditions affecting $>1$ region. Only when no lesion is found and in the absence of other organic clinical features should functional causes then be considered.

\section{Types of Visual Hallucinations}

A hallucination is a "percept without object," "a sensory perception that has the compelling sense of reality but that occurs without stimulation of the relevant sensory organ." ${ }^{2}$ Hallucinations are distinguished from the following: 1) distortions, in which the real objects are perceived as changed in some way; 2) illusions, in which the perception of real objects is transformed in size (micropsia or macropsia), shape (metamorphopsia), or color (dyschromasia) or into other objects; or 3) pseudohallucinations, which arise from vivid inner mental experience and can often be recognized as such. Although hallucinations are experienced as real, patients experiencing them have varying degrees of insight into the nature of their experiences, which engender varying responses, from indifference to marked distress. Hallucinations vary in content and complexity and occur in every sensory technique: Visual hallucinations are commonly linked to underlying organic etiology but also occur frequently in psychotic states, though half as commonly as auditory hallucinations. Olfactory, tactile, and gustatory hallucinations occur 
less often and are seen in a variety of both psychiatric and organic conditions. The use of the term "organic" here is by convention and should not be taken to imply an absence of brain dysfunction in psychiatric illness. ${ }^{3}$

The content of visual hallucinations can offer some clue as to their origin (Table 1) and may relate to the mechanism of production.

Table 1: Type of hallucination

\begin{tabular}{ll}
\hline \multicolumn{1}{c}{ Feature } & \multicolumn{1}{c}{ Possible Cause } \\
\hline Monocular & $\begin{array}{c}\text { Eye disease or optic nerve proximal to } \\
\text { optic chiasm } \\
\text { Limited visual field }\end{array}$ \\
$\begin{array}{l}\text { Focal lesion in visual pathway } \\
\text { Eye disease, migraine, seizure, calcarine } \\
\text { lesions } \\
\text { Visual distortion }\end{array}$ & $\begin{array}{c}\text { Seizures, CJD } \\
\text { Delirium, intoxication, withdrawal }\end{array}$ \\
Lilliputian & $\begin{array}{l}\text { Delirium, hallucinogens, psychosis } \\
\text { Frightening }\end{array}$ \\
$\begin{array}{l}\text { Unconcerned/preserved } \\
\text { insight }\end{array}$ & $\begin{array}{c}\text { Charles Bonnet syndrome, peduncular } \\
\text { hallucinosis }\end{array}$ \\
\hline
\end{tabular}

Simple Visual Hallucinations. Brief, stereotyped unformed flashes of light and color or indistinct forms may reflect stimulation or irritation of primary visual areas, for example by tumor, migraine, or focal epileptogenic lesions.

Complex Visual Hallucinations. In contrast, complex visual hallucinations suggest disruption to the wider visual system ${ }^{4}$ and include branching or tessellated patterns, individuals or crowds of people, animals, and complex scenes often associated with sensory distortions. Lilliputian hallucinations, classically seen in alcohol withdrawal and delirium, are complex VHs consisting of miniature people in lines or groups performing strange actions and eliciting curiosity or wonder. Complex VHs due to psychiatric disturbance, delirium, or intoxication/withdrawal are often perceived as real and frightening, while those seen in peduncular hallucinosis or the Charles Bonnet syndrome may provoke indifference, and insight into the nature of the experience as unreal may be preserved. Associated symptoms such as headaches or focal seizures may help point toward a specific etiology, as may the presence of associated deteriorating cognitive function, focal neurologic symptoms, or psychiatric symptoms (Table 2).

\begin{tabular}{ll}
\hline \multicolumn{1}{c}{ Feature } & \multicolumn{1}{c}{ Possible Cause } \\
\hline Vision loss & Charles Bonnet syndrome \\
Headache, nausea/vomiting & Migraine \\
Impaired/fluctuating level of & Delirium, epilepsy \\
consciousness & Delirium, intoxication, encephalopathy, dementia \\
$\begin{array}{l}\text { Confusion/disorientation } \\
\text { Focal neurologic signs }\end{array}$ & $\begin{array}{l}\text { Space-occupying lesion } \\
\text { Agitation, depression, mania, anxiety, }\end{array}$ \\
$\begin{array}{l}\text { disordered/unusual thought content } \\
\text { Delirium, intoxication, psychiatric disorders } \\
\text { (psychosis, severe mood disorders) }\end{array}$ \\
\hline
\end{tabular}

\section{Visual Pathway and Mechanisms of Disruption}

The anatomy of the primary visual pathway is well-described: Information from the retina passes along the optic nerve, chiasm, and tract to the lateral genicu-
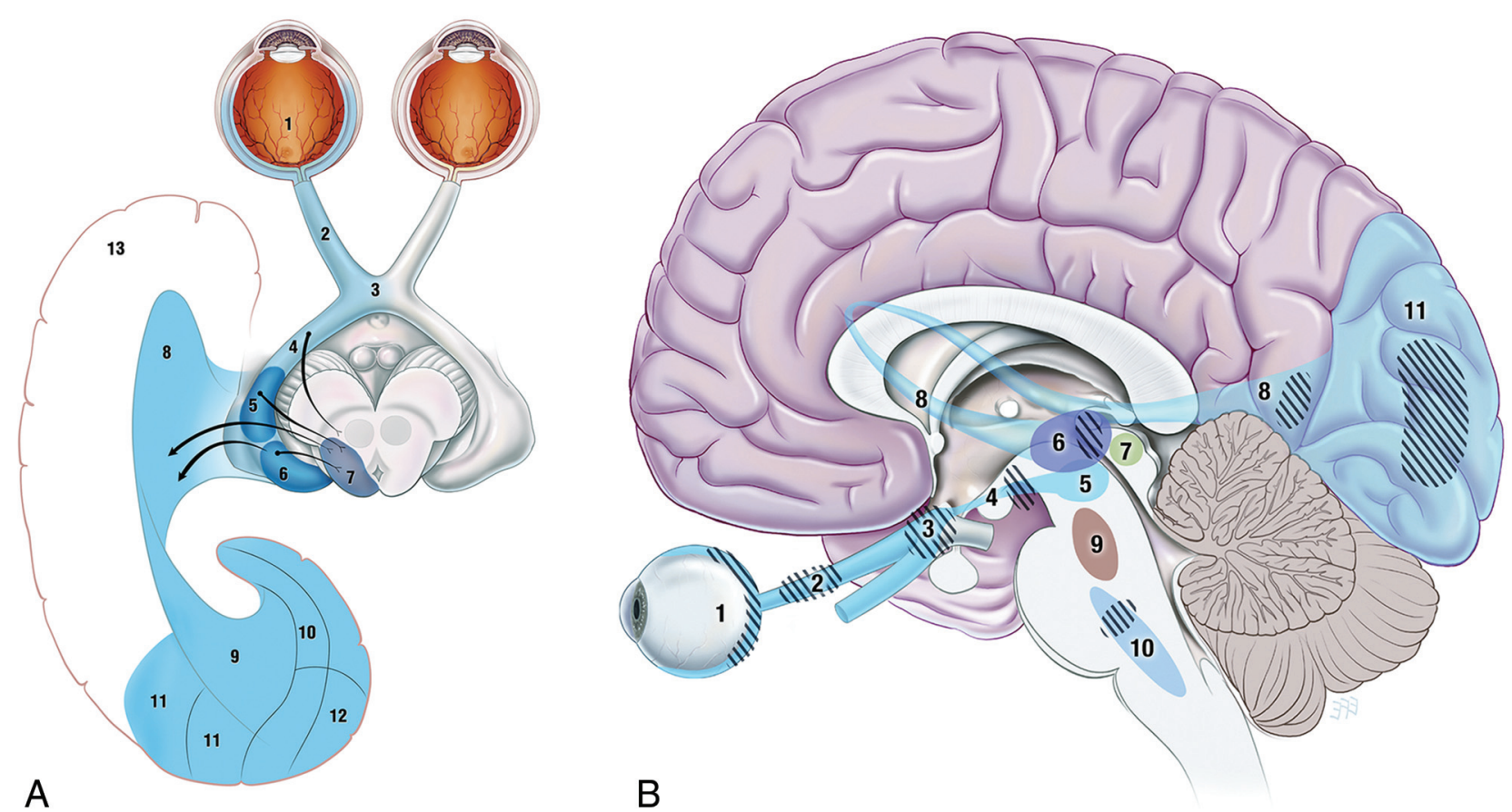

FIG 1. Visual pathways. A, Retino-geniculo-calcarine tract. Optical information from the retina (1) passes along the optic nerve (2) through the optic chiasm (3) and optic tract (4) into the lateral geniculate nucleus of the thalamus (5), where it receives input from the superior colliculus (7) via the pulvinar (6) and then traverses the optic radiation ( 8 and 9) through the temporal lobe (13) into the visual cortex (10-12). B, Intersection of ascending pathways. Optical information in the retino-geniculo-calcarine tract (1-8 and 11) is modulated by ascending input from the pedunculopontine and parabrachial nuclei (9) and raphe nuclei (10) via the superior colliculus (7). Hashed areas show regions where interruptions are known to produce visual hallucinations: in the retino-geniculo-calcarine tract via deafferentation, in the thalamus through reducing signal-to-noise ratio, and in the ascending pathways via removal of inhibitory control. Reproduced with permission from Dr. Ramon Mocellin. 
late nucleus in the thalamus and then to the optic radiation through the temporal lobe to the primary and secondary visual cortices (Fig 1). The flow of visual information is modulated by ascending input from the pedunculopontine and parabrachial nuclei and raphe nuclei via the superior colliculi (Fig 2) and involves the cholinergic, GABAergic, and glutamateric systems (Fig 2).

Interruptions to this system at any point, either in the primary direct pathway or in its ascending modulatory projections, may lead to visual hallucinations. One series by Braun et $\mathrm{al}^{5}$ suggested that the occipital and occipitotemporal regions were the most commonly implicated cortical regions, and the midbrain, cerebral

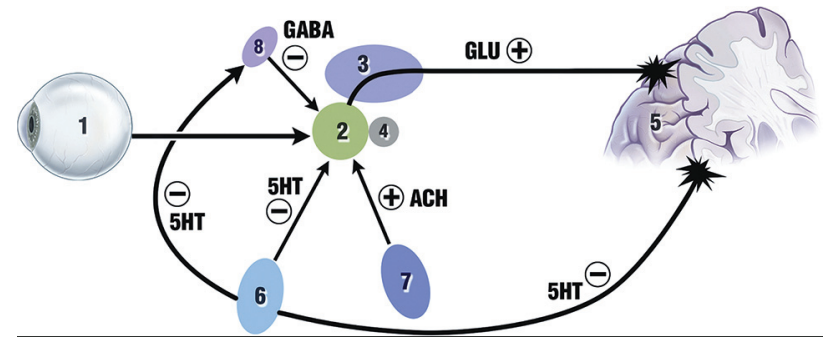

FIG 2. Neurochemistry of vision. Input from the retina (1) reaches the lateral geniculate nucleus of the thalamus (2). This structure and the adjacent pulvinar of the thalamus (3), an accessory visual structure that may act to filter out eye-movement "noise," act as a junction between retino-geniculo-calcarine and ascending brain stem circuits, receiving inhibitory serotonergic input from the raphe nuclei (6) and excitatory cholinergic input from the pedunculopontine and parabrachial nuclei (7). The reticular nucleus of the thalamus (8) also provides inhibitory GABAergic innervation to the geniculate, which is itself modulated by the same ascending cholinergic and serotonergic input. The glutamatergic excitatory circuits from the geniculate to the occipital cortex (5) are also modulated by the superior colliculus (4). Reproduced with permission from Dr. Ramon Mocellin.
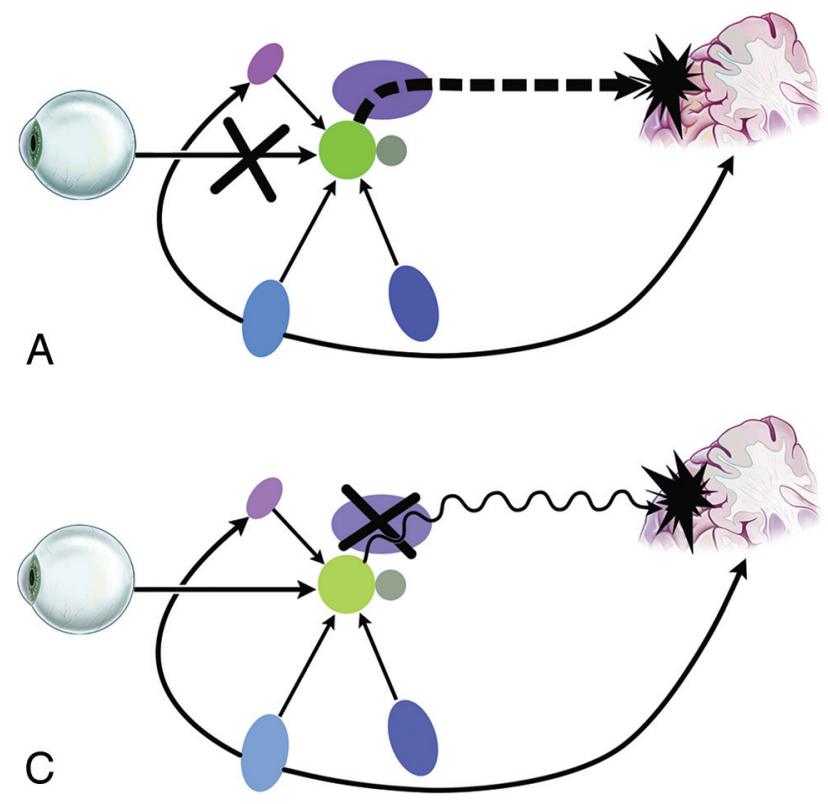

peduncles, pons, and thalamus, the usual subcortical regions. A search for focal lesions on MR imaging should progress with this pathway in mind.

The exact mechanisms underlying these hallucinations remain unclear but may involve cortical release or deafferentation phenomena (Fig $3 A)^{6}$ and/or the disinhibition of projections from ascending pathways or the intact nearby visual cortex. Disruption of ascending input, for example at the lateral geniculate nucleus, may lead to aberrant projections forward to the visual cortex (Fig $3 B$ ) or a loss of central sensory filtering function and degradation of signal to noise (Fig 3C).

\section{Focal Causes of Visual Hallucinations}

Retinal Pathology. Traction, irritation, injury, or disease of the retina can stimulate retinal photoreceptors, causing brief simple hallucinations in the form of flashes, sparks, or streaks of light. Often both the condition and hallucinations are monocular, and insight is invariably preserved.

Charles Bonnet Syndrome. In 1769, Charles Bonnet described complex VHs of people, birds, and buildings in his cataract-affected grandfather and later experienced similar phenomena himself. ${ }^{7}$ The Charles Bonnet syndrome describes a wide variety of VHs associated with visual impairment of any cause-in clear sensorium, with retained insight and without other psychopathology. Typically the visions are colorful images of people, animals, and inanimate objects, occurring especially later in the day, in poor light, or in isolation. Charles Bonnet syndrome has been reported in $12 \%-65 \%$ of visually impaired individuals, particularly in women and with increasing age (mean onset at 74.5 years) and reduced cognitive reserve, with white matter lesions on MR imaging, and with polypharmacy. ${ }^{8,9}$ Although Charles Bonnet

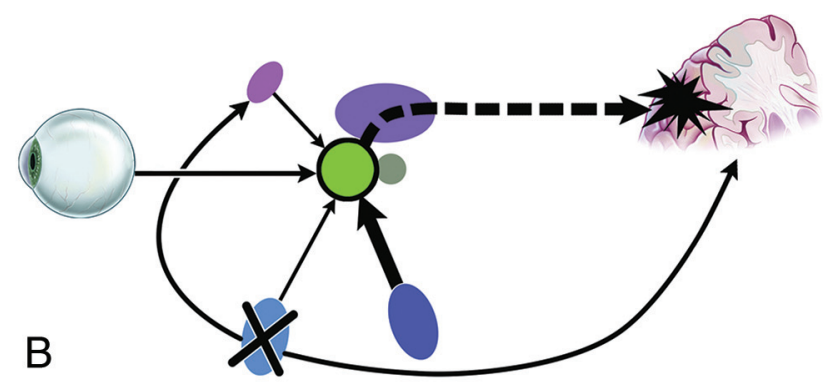

FIG 3. Possible mechanisms of visual hallucinations. $A$, Deafferentation: lesions responsible for pathway complex visual hallucination in which deafferentation from ocular input results in "release" activity in the cortex. B. Disinhibition: lesions responsible for ascending complex visual hallucinations in which a loss of ascending inhibition to the geniculate results in a hyperexcited geniculate and excess glutamatergic activity in the optic radiation, with resultant poor-quality signal to the cortex. C, Central: lesions producing central complex visual hallucinations in which damage to the geniculate may again "deafferent" the striate cortex and lesions to the pulvinar of the thalamus may reduce the signal-to-noise ratio of cortical input due to a loss of the visual filter function of the pulvinar. Reproduced with permission from Dr. Ramon Mocellin. 
syndrome was initially described in ocular causes of reduced visual input, more recently the term is increasingly used as a catchall denoting complex VHs arising from lesions affecting vision anywhere along the primary visual pathway from the retina onward. The frequency of underlying causes reflects the most prevalent conditions affecting vision, particularly in the elderly: age-related macular degeneration, glaucoma, diabetic retinopathy, and cerebral infarction. ${ }^{8,9}$

Imaging Features. A discussion of all causes of Charles Bonnet syndrome is clearly beyond the scope of this article, and many cases will be obvious. A careful review of the globes, usually not the focus of attention in patients undergoing brain imaging, is however useful in potentially alerting the clinician to causes of visual loss as an etiology of complex visual hallucinations. Calcified optic nerve drusen (hyaline calcific deposits) are usually incidental findings; however, they may sometimes be associated with visual field loss or macular degeneration and appear on CT as punctate calcifications at the optic nerve insertion. ${ }^{10}$ Phthisis bulbi, from prior trauma or infection, may be evident as a small hyperattenuated globe, with a thickened and calcified sclera. Chronic retinal detachment typically appears as subretinal fluid of variable attenuation on CT and signal intensity on MR imaging. Evidence of a prior ocular operation may be evident in the form of scleral buckling or intraocular lens replacement.

Space-Occupying and Vascular Lesions. Structural disruptions to the visual pathway, for example from neoplastic or vascular lesions, may also lead to complex VHs. In some cases, these are the result of reduced visual input (Charles Bonnet syndrome), whereas in many other instances, the lesions result in VHs without significant loss of vision, supporting the concept of a cortical release of activity from the intact neighboring visual cortex. In historical case series, approximately one-fourth of patients with temporal lobe tumors ${ }^{11}$ and $15 \%$ with occipital tumors ${ }^{12}$ had VHs, the latter usually simpler in content. Posterior cerebral artery infarction leading to lesions in the occipital cortex or visual thalamus may also lead to VHs, usually restricted to the abnormal visual field. ${ }^{13}$ In most cases, the hallucinations came days to weeks after the initial infarct and resolved during a period of weeks.

Peduncular Hallucinosis. These complex and vivid hallucinations arise in the context of lesions in the midbrain pons or thalamus, not just the cerebral peduncles. They can be due to a wide range of pathologic states, including vascular, infectious, neoplastic, and compressive lesions. ${ }^{14,15}$ These lead to visual hallucinations via disruptions to ascending inputs to the visual pathway, such as inhibitory afferents to the dorsal lateral geniculate nucleus, which then project aberrantly to the visual cortex (Fig 3B).

Imaging Features. Attention should be paid to the brain stem, in particular the cerebral peduncles, pons, and midbrain, for intrinsic or compressive pathology. Peduncular hallucinosis has been reported following infarcts affecting the cerebral peduncle, as well as compression from lesions such as medulloblastoma and meningioma. $^{15}$

Posterior Cortical Seizures. Aberrant electrical activity arising anywhere along the primary or ascending visual pathways leading to focal seizures may result in VHs. Occipital seizures, occurring in approximately $5 \%$ of patients with epilepsy, ${ }^{16}$ are frequently associated with visual manifestations. These are often experienced as simple brief fragmentary stereotyped flashing lights, patterns, or blobs of color or distortions and illusions. Seizures associated with complex VHs suggest involvement of the secondary visual cortex or may arise in association with other symptoms of a periictal psychosis. ${ }^{15}$

Migraine. Between $15 \%$ and $30 \%$ of people with migraines experience auras; of these, $90 \%$ are visual. ${ }^{17-19}$ As with seizures, visual hallucinations and distortions associated with migraine aura are usually simple: The classic aura is of a flickering central zigzag line or crescent progressing peripherally, leaving a central scotoma. Colored patterns and more complex hallucinations may also occur, particularly in rarer causes of migraine, such as familial hemiplegic migraine and migraine coma. Spreading depression of cortical activity may be important in the generation of an aura, with pathologic excitation in visual areas responsible for complex VHs in migraine. ${ }^{15}$ Notable neuroimaging findings in migraine are well described. ${ }^{20,21}$

Posterior Reversible Encephalopathy Syndrome. Posterior reversible encephalopathy syndrome is a radiologic and clinical neurotoxic state secondary to failure of cerebral autoregulation in response to acute changes in blood pressure in patients with eclampsia and posttransplantation states and in a range of other conditions. ${ }^{22}$ While visual symptoms (including cortical blindness, homonymous hemianopia, blurred vision, and neglect) are relatively common, ${ }^{23}$ hallucinations are less common, though several cases including complex VHs have been reported. ${ }^{24}$ Diagnosis relies on strong clinical suspicion and characteristic MR imaging/CT features. Patients may present with severe headache, confusion, visual disturbance, nausea, vomiting, and seizures; recovery occurs relatively quickly following treatment, with resolution of both clinical and radiologic deficits. ${ }^{23}$ Key neuroimaging features in posterior reversible encephalopathy syndrome are well known (On-line Fig 1). ${ }^{25}$

Reversible Cerebral Vasoconstriction Syndromes. Reversible cerebral vasoconstriction syndromes encompass Call-Fleming syndrome (reversible cerebral arterial segmental vasoconstriction), migrainous vasospasm, benign angiopathy of the central nervous system, postpartum angiopathy, and drug-induced arteritis. ${ }^{26,27}$ These conditions share underlying reversible segmental or multifocal cerebral vasoconstriction and carry the risk of ischemic deficits because of vasoconstriction. Patients may present with sudden-onset posterior thunderclap headache (with or without associated neurologic symptoms) and/or recurrent headaches associated with nausea, vomiting, photophobia, and phonophobia. $^{27,28}$ Visual hallucinations are a rare manifestation, though again cases have been reported. ${ }^{29}$ Important neuroimaging features of reversible cerebral vasoconstriction syndromes are widely known. ${ }^{30}$

\section{Global Causes of Visual Hallucinations}

Visual hallucinations arise in a wide range of other neurologic and systemic disorders, due to localized structural disruption from neurofibrillary tangles or synuclein deposition or to widespread 
neurochemical derangement in neurometabolic disorders, intoxication/withdrawal states, and delirium.

Synucleinopathies with Lewy Body Formation. Synucleinopathies are a diverse group of related neurodegenerative diseases with a high incidence of VHs characterized by abnormal $\alpha$-synuclein metabolism, which, in some instances, results in the formation of intracellular inclusions known as Lewy bodies. ${ }^{31,32}$ The number and distribution of Lewy bodies, particularly in mesial temporal structures, are associated with the frequency of VHs. ${ }^{33}$ VHs may also relate to synuclein deposition in visual areas, altered ascending input from loss of serotonergic and cholinergic brain stem nuclei, and the use of dopaminergic medications. $^{34}$ In contrast, synucleinopathies without Lewy bodies, such as multisystem atrophy, have a low incidence of visual hallucinations. ${ }^{35}$

Lewy Body Dementia. Lewy body dementia is the second most common form of dementia after Alzheimer disease. Visual hallucinations form part of the core clinical diagnostic criteria for Lewy body dementia and are typically seen early in the course of the disease, before the development of Parkinsonian motor symptoms. ${ }^{36}$ The incidence of VHs in Lewy body dementia varies between $20 \%$ and $75 \%,{ }^{31,33,35}$ and the presence of $\mathrm{VH}$ provides an $83 \%$ positive predictive value for distinguishing Lewy body dementia from Alzheimer disease. ${ }^{37} \mathrm{VHs}$ in Lewy body dementia typically manifest as prolonged well-formed complex scenes of figures and objects and provoke varied reactions from fear through to indifference.

Imaging Features. A lack of mesial temporal atrophy in Lewy body dementia is perhaps the most useful finding in distinguishing Lewy body dementia from Alzheimer disease. ${ }^{38-40}$ A pattern of relatively focused atrophy of the midbrain, hypothalamus, and substantia innominata, with a relative sparing of the hippocampus and temporoparietal cortex, may be seen (On-line Fig 2).

Parkinson Disease/Parkinson Disease Dementia. Parkinson disease is one of the most common neurodegenerative diseases, seen in $1 \%$ of patients older than 60 years of age. ${ }^{41}$ Patients may present with the classic motor triad of tremor at rest, rigidity, and hypokinesia, as well as a range of nonmotor symptoms. VHs are common and occur in 25\%-50\% of patients with Parkinson disease ${ }^{42}$ and are similar in content to those of Lewy body dementia, ranging from people or animals to complex, formed, and animated scenes.

Imaging Features. In most instances, imaging plays a supportive role in the diagnosis of Parkinson disease, ${ }^{39}$ which is usually established clinically. Loss of normal susceptibility-induced signal drop-out in the substantia nigra pars compacta on $\mathrm{T} 2{ }^{*}$-weighted images is potentially the most useful feature, but this has been difficult to demonstrate reliably. ${ }^{43}$ Other features include mild T1 signal hyperintensity of the reticular parts of the substantia nigra and red nuclei and dotlike areas of hyperintensity in the compact part of the substantia nigra; however, the clinical utility of such findings is limited because they are subtle and are only reported late in the disease. ${ }^{44,45}$

Alzheimer Disease/Posterior Cortical Atrophy. VHs may also be seen in Alzheimer disease, particularly in patients with advanced disease and when combined with confusion and loss of visual acuity. ${ }^{37,46}$ VHs in Alzheimer disease may result from Alzheimer plaques and tangles in the visual-association cortices and have been associated with periventricular white matter lesions and occipital atrophy. ${ }^{47,48}$

VHs are seen in approximately $25 \%$ of patients diagnosed with the posterior cortical atrophy variant of Alzheimer disease, in which cortical loss is localized, particularly to the occipital and parietal lobes, leading to visual agnosia and apraxia. ${ }^{49}$ Those patients with posterior cortical atrophy and complex VHs have disproportionate involvement of the midbrain, thalamus, and primary visual cortex, and interplay between these regions may be responsible. ${ }^{49}$

Imaging Features. Cortical atrophy tends to occur within the mesial temporal structures, with widening of the parahippocampal fissures. SPECT and FDG-PET examinations demonstrate reduced bitemporoparietal uptake, reflecting reduced cerebral blood flow. The presence of parietal-predominant volume loss is suggestive of the posterior cortical atrophy variant. ${ }^{50} \mathrm{MR}$ imaging demonstrates gray matter atrophy involving the occipital, parietal, and posterior temporal lobes, often more pronounced on the right side (On-line Fig 3$).{ }^{51}$ In patients with visual hallucinations, additional regions involved include the primary visual cortex, thalamus, basal nuclei, midbrain, basal forebrain, and posterior frontal and medial temporal lobes. ${ }^{49}$

Frontotemporal Lobar Degeneration. Frontotemporal lobar degeneration covers a spectrum of genetically and neuropathologically heterogeneous disorders, including behavioral variant frontotemporal dementia, semantic dementia, and progressive nonfluent aphasia. ${ }^{52}$ Frontotemporal lobar degeneration leads primarily to personality and behavioral changes and language disturbance but also to psychotic symptoms in $10 \%-30 \%$ of cases $^{53,54}$ and visual hallucinations in up to $14 \% .^{54}$ Psychotic symptoms are more prevalent in carriers of the C9orf72 mutation, whose thalamus and cerebellum are more frequently affected. ${ }^{55}$ VHs are more common in the right than in the left temporal variant frontotemporal lobar degeneration, ${ }^{56}$ often associated with delusions. ${ }^{57}$

Imaging Features. While atrophy in the anterior temporal and medial frontal lobes is characteristic of frontotemporal lobar degeneration (On-line Fig 4), ${ }^{58}$ specific imaging findings can reflect underlying subtypes. Bilaterally symmetric or right frontal atrophy is seen in the behavioral subtype. In the semantic dementia subtype, there is anterior temporal-predominant atrophy. Left dominant atrophy is seen if speech apraxia predominates, with right dominant atrophy if prosopagnosia predominates. ${ }^{40}$ Frontostriatal dysfunction also varies among these different subtypes, with the behavioral variant having the greatest involvement: Caudate heads are relatively reduced in size in these patients compared with those with the language variant of frontotemporal lobar degeneration. ${ }^{59}$

Creutzfeldt-Jakob Disease. In Creutzfeldt-Jakob disease, a rare, rapidly progressive neurodegenerative condition caused by prion infection, VHs may accompany the typical rapid cognitive decline, anxiety, personality change, myoclonic jerks, and ataxia. ${ }^{60}$ Visual effects may include color changes, field defects, visual ag- 
nosia, and distortions progressing to frank hallucinations, ${ }^{61}$ seen particularly in the Heidenhain variant of CJD and associated with periodic electroencephalography complexes over the occipital region. ${ }^{62}$

Imaging Features. Sporadic CJD classically results in cortical diffusion restriction as the earliest imaging manifestation (Online Fig 5), which may be bilateral or unilateral, symmetric or asymmetric. Bilateral areas of increased signal intensity predominantly affecting the caudate nuclei and the putamina should also suggest the diagnosis of CJD. ${ }^{63}$ In variant CJD, FLAIR/T2 hyperintensity may be demonstrated in the pulvinar nuclei bilaterally (pulvinar sign) and both the dorsomedial thalamus and pulvinar (hockey stick sign). ${ }^{64,65}$

Intoxication, Withdrawal, and Delirium. Delirium tremens, seen in severe alcohol withdrawal, is associated with frightening VHs, tremor, autonomic disturbance, and agitation. ${ }^{15}$ Similar withdrawal states may follow the sudden cessation of benzodiazepines or barbiturates, suggesting a shared role of altered $\gamma$-aminobutyric acid signaling. ${ }^{66}$ Drugs such as lysergic acid diethylamide and mescaline have hallucinogenic properties correlated with their serotonergic activity and lead to colored patterns, distortions, and illusions that progress to include complex scenes of animals and people. These are often vivid and associated with heightened sensory arousal, with preserved insight and without paranoia or delusional interpretation. Cocaine and amphetamines in contrast, which act to increase synaptic dopamine transmission, tend to produce VHs with heightened paranoia and agitation. $^{66}$

Delirium is a syndrome of disturbed consciousness and impaired attention associated with a raft of metabolic, infectious, toxic, and intracranial causes. ${ }^{67}$ Hallucinations are often a prominent part of this syndrome and are typically visual, with vivid, complex, and often frightening scenes of people and animals that may be accompanied by paranoia and fleeting delusions. ${ }^{66}$

Imaging Features. In most cases of intoxication, withdrawal, and delirium, imaging is performed to rule out underlying structural pathology. MR imaging in Wernicke-Korsakoff syndrome, induced by thiamine deficiency in starvation and alcoholism, demonstrates T2 hyperintensity in the mammillary bodies, thalami, periaqueductal gray tectal plate, and dorsal medulla, with possible associated contrast enhancement. ${ }^{68}$

\section{Psychiatric and Other Causes of Visual Hallucinations}

Once focal and global brain pathology has been excluded with MR imaging and other investigations, psychiatric causes including major affective and psychotic disorders should be considered. Brain MR imaging findings are usually normal. ${ }^{69}$ In schizophrenia, VHs are around half as common as auditory hallucinations; when experienced by people with schizophrenia, VHs are also usually accompanied by auditory hallucinations. ${ }^{70,71}$ In one sample, visual hallucinations were present in $16 \%$ of subjects and were related to the severity of illness. ${ }^{72}$ Visual hallucinations are also common in states of reduced consciousness, such as entering and awakening from sleep, particularly in the presence of sleep disor-
Table 3: Reported incidence of visual hallucinations in various conditions

\begin{tabular}{ll}
\hline \multicolumn{1}{c}{ Condition } & \multicolumn{1}{c}{ Incidence of VH } \\
\hline Lewy body dementia & $20 \%-75 \%^{31,33,35}$ \\
Parkinson disease & $15 \%-75 \%^{35}$ \\
PCA/AD & $25 \%^{49}$ \\
FTD & $10 \%-14 \%^{54}$ \\
Occipital seizures & $\leq 100 \%^{16}$ \\
Migraine & $90 \%$ with visual aura ${ }^{17-19}$, CVH rarer \\
PRES & Case reports only ${ }^{23,24}$ \\
RVCS & Case reports only ${ }^{24}$ \\
\hline
\end{tabular}

Note:-PCA indicates posterior cortical atrophy; AD, Alzheimer disease; FTD, frontotemporal dementia; $\mathrm{CVH}$, complex visual hallucination; PRES, posterior reversible encephalopathy syndrome; RCVS, reversible cerebral vasoconstriction syndrome.

ders, ${ }^{73}$ and may be induced by prolonged visual deprivation, a syndrome akin to that described in Charles Bonnet syndrome.

\section{Conclusions and Imaging Recommendations}

Considering the range of focal and global pathology that can result in VHs, a sensible approach to imaging is needed (On-line Table). Often the type or features of VHs being experienced are not indicated on imaging requests, so highly targeted protocols are unreliable. Instead, we recommend a relatively generic approach able to adequately image the entire optic pathway and identify, if not necessarily fully characterize, all likely pathologies. The key sequences are high-resolution T1 and T2/FLAIR, preferably isotropic volumetric imaging, susceptibility-weighted imaging, and diffusion-weighted imaging. Time permitting, additional catchall sequences may be added (eg, MR perfusion, double inversion recovery, MRA).

A systematic approach to the review of these sequences with regard to direct and ascending visual pathways looking first for focal and patterns of global pathologies outlined above will ensure detection of the most important pathology underlying the presentation of visual hallucinations (Table 3 ).

Disclosures: Toby T. Winton-Brown—UNRELATED: Grants/Grants Pending: Wellcome Trust, UK (Research Training Fellowship, WT087779MA). Dennis VelakoulisUNRELATED: Royalties: Neuropsychiatry Unit Cognitive Assessment Tool; Stock/ Stock Options: Prana Biotechnology Ltd, a company with research into neurodegenerative disorders. Frank Gaillard-UNRELATED: Employment: Radiopaedia. org (Founder, Editor, and CEO).

\section{REFERENCES}

1. Esquirol E. Des Maladies Mentales Considérées sous les Rapports Médical, Hygiénique et Médico-Légal. Paris: JB Baillière; 1838

2. American Psychiatric Association; American Psychiatric Association. Task Force on DSM-IV. Diagnostic and Statistical Manual of Mental Disorders. Washington: American Psychiatric Association; 2000

3. Sachdev P. A critique of 'organic' and its proposed alternatives. Aust N Z J Psychiatry 1996;30:165-70 Medline

4. Santhouse AM, Howard RJ, ffytche DH. Visual hallucinatory syndromes and the anatomy of the visual brain. Brain 2000:123(pt 10): 2055-64 CrossRef Medline

5. Braun CM, Dumont $M$, Duval J, et al. Brain modules of hallucination: an analysis of multiple patients with brain lesions. J Psychiatry Neurosci 2003;28:432-49 Medline

6. West LJ. A general theory of hallucinations and dreams. In: West LJ, ed. Hallucinations. Oxford: Grune \& Stratton; 1962: 275-90

7. Bonnet C. Essai Analytique sur les Facultés de L'Âme. Copenhagen: Philibert; 1760:426-28

8. Teunisse RJ, Cruysberg JR, Hoefnagels WH, et al. Visual hallucina- 
tions in psychologically normal people: Charles Bonnet's syndrome. Lancet 1996:347:794-97 Medline

9. Menon GJ. Complex visual hallucinations in the visually impaired: a structured history-taking approach. Arch Ophthalmol 2005;123: 349-55 CrossRef Medline

10. LeBedis CA, Sakai O. Nontraumatic orbital conditions: diagnosis with $\mathrm{CT}$ and MR imaging in the emergent setting. Radiographics 2008;28:1741-53 CrossRef Medline

11. Cushing H. Distortions of the visual field in cases of brain tumour (6th paper): the field defects produced by temporal lobe lesions. Brain 1922;44:341-96 CrossRef

12. Parkinson D, Rucker CW, Craig WM. Visual hallucinations associated with tumors of the occipital lobe. AMA Arch Neurol Psychiatry 1952;68:66-68 CrossRef Medline

13. Vaphiades MS, Celesia GG, Brigell MG. Positive spontaneous visual phenomena limited to the hemianopic field in lesions of central visual pathways. Neurology 1996;47:408-17 CrossRef Medline

14. Mocellin R, Walterfang M, Velakoulis D. Neuropsychiatry of complex visual hallucinations. Aust N Z J Psychiatry 2006;40:742-51 CrossRef Medline

15. Manford M, Andermann F. Complex visual hallucinations: clinical and neurobiological insights. Brain 1998;121(pt 10):1819-40 CrossRef Medline

16. Panayiotopoulos CP. Elementary visual hallucinations, blindness, and headache in idiopathic occipital epilepsy: differentiation from migraine. J Neurol Neurosurg Psychiatry 1999;66:536-40 CrossRef Medline

17. Rasmussen BK, Olesen J. Symptomatic and nonsymptomatic headaches in a general population. Neurology 1992;42:1225-31CrossRef Medline

18. Goadsby PJ, Lipton RB, Ferrari MD. Migraine: current understanding and treatment. $N$ Engl J Med 2002;346:257-70 CrossRef Medline

19. Kelman L. The aura: a tertiary care study of $\mathbf{9 5 2}$ migraine patients. Cephalalgia 2004;249728-34 Medline

20. Rocca MA, Ceccarelli A, Falini A, et al. Brain gray matter changes in migraine patients with T2-visible lesions: a 3-T MRI study. Stroke 2006;37:1765-70 CrossRef Medline

21. Kruit MC, Launer LJ, Ferrari MD, et al. Infarcts in the posterior circulation territory in migraine: the population-based MRI CAMERA study. Brain 2005;128(pt 9):2068-77 CrossRef Medline

22. Bartynski WS. Posterior reversible encephalopathy syndrome, part 1: fundamental imaging and clinical features. AJNR Am J Neuroradiol 2008;29:1036-42 CrossRef Medline

23. Hinchey J, Chaves C, Appignani B, et al. A reversible posterior leukoencephalopathy syndrome. $N$ Engl J Med 1996;334:494-500 CrossRef Medline

24. Tallaksen C, Kerty E, Bakke S. Visual hallucinations in a case of reversible hypertension-induced brain oedema. Eur J Neurol 1998; 5:615-18 CrossRef Medline

25. Hugonnet E, Da Ines D, Boby H, et al. Posterior reversible encephalopathy syndrome (PRES): features on CT and MR imaging. Diagn Interv Imaging 2013;94:45-52 CrossRef Medline

26. Calabrese LH, Gragg LA, Furlan AJ. Benign angiopathy: a distinct subset of angiographically defined primary angiitis of the central nervous system. J Rheumatol 1993;20:2046-50 Medline

27. Ducros A. Reversible cerebral vasoconstriction syndrome. Lancet Neurol 2012;11:906-17 CrossRef Medline

28. Singhal AB, Hajj-Ali RA, Topcuoglu MA, et al. Reversible cerebral vasoconstriction syndromes: analysis of 139 cases. Arch Neurol 2011;68:1005-12 CrossRef Medline

29. Yagi Y, Watanabe Y, Yokote H, et al. Transient Charles Bonnet syndrome in a patient with reversible cerebral vasoconstriction syndrome. Neurol Sci 2013;34:1023-25 CrossRef Medline

30. Ducros A, Fiedler U, Porcher R, et al. Hemorrhagic manifestations of reversible cerebral vasoconstriction syndrome: frequency, features, and risk factors. Stroke 2010;41:2505-11 CrossRef Medline

31. Jellinger KA. Neuropathological spectrum of synucleinopathies. Mov Disord 2003:18(suppl 6):S2-12 Medline
32. Martí MJ, Tolosa E, Campdelacreu J. Clinical overview of the synucleinopathies. Mov Disord 2003;18(suppl 6):S212 Medline

33. Harding AJ, Broe GA, Halliday GM. Visual hallucinations in Lewy body disease relate to Lewy bodies in the temporal lobe. Brain 2002: 125(pt 2):391-403 CrossRef Medline

34. Zahodne LB, Fernandez DHH. Pathophysiology and treatment of psychosis in Parkinson's disease: a review. Drugs Aging 2008;25: 665-82 CrossRef Medline

35. Bertram K, Williams DR. Visual hallucinations in the differential diagnosis of parkinsonism. J Neurol Neurosurg Psychiatry 2012;83: 448-52 CrossRef Medline

36. McKeith I, Mintzer J, Aarsland D, et al; International Psychogeriatric Association Expert Meeting on DLB. Dementia with Lewy bodies. Lancet Neurol 2004;3:19-28 CrossRef Medline

37. Tiraboschi P, Salmon DP, Hansen LA, et al. What best differentiates Lewy body from Alzheimer's disease in early-stage dementia? Brain 2006:129(pt 3):729-35 CrossRef Medline

38. Taylor JP, O’Brien J. Neuroimaging of dementia with Lewy bodies. Neuroimaging Clin N Am 2012:22:67-81, viii CrossRef Medline

39. Broski SM, Hunt CH, Johnson GB, et al. Structural and functional imaging in parkinsonian syndromes. Radiographics 2014;34: 1273-92 CrossRef Medline

40. Atlas SW. Magnetic Resonance Imaging of the Brain and Spine. Philadelphia: Wolters Kluwer Health/Lippincott Williams \& Wilkins; 2009

41. Connolly BS, Lang AE. Pharmacological treatment of Parkinson disease: a review. JAMA 2014;311:1670-83 CrossRef Medline

42. Williams DR, Lees AJ. Visual hallucinations in the diagnosis of idiopathic Parkinson's disease: a retrospective autopsy study. Lancet Neurol 2005;4:605-10 CrossRef Medline

43. Minati L, Grisoli M, Carella F, et al. Imaging degeneration of the substantia nigra in Parkinson disease with inversion-recovery MR imaging. AJNR Am J Neuroradiol 2007;28:309-13 Medline

44. Adachi M, Hosoya T, Haku T, et al. Evaluation of the substantia nigra in patients with Parkinsonian syndrome accomplished using multishot diffusion-weighted MR imaging. AJNR Am J Neuroradiol 1999;20:1500-06 Medline

45. Schwarz ST, Rittman T, Gontu V, et al. T1-weighted MRI shows stage-dependent substantia nigra signal loss in Parkinson's disease. Mov Disord 2011;26:1633-38 CrossRef Medline

46. Chapman FM, Dickinson J, McKeith I, et al. Association among visual hallucinations, visual acuity, and specific eye pathologies in Alzheimer's disease: treatment implications. Am J Psychiatry 1999; 156:1983-85 Medline

47. Lin SH, Yu CY, Pai MC. The occipital white matter lesions in Alzheimer's disease patients with visual hallucinations. Clin Imaging 2006:30:388-93 CrossRef Medline

48. Holroyd S, Shepherd ML, Downs JH. Occipital atrophy is associated with visual hallucinations in Alzheimer's disease. J Neuropsychiatry Clin Neurosci 2000;12:25-28 CrossRef Medline

49. Josephs KA, Whitwell JL, Boeve BF, et al. Visual hallucinations in posterior cortical atrophy. Arch Neurol 2006;63:1427-32 CrossRef Medline

50. Crutch SJ, Lehmann M, Schott JM, et al. Posterior cortical atrophy. Lancet Neurol 2012;12:170-78 CrossRef Medline

51. Whitwell JL, Jack CR Jr, Kantarci K, et al. Imaging correlates of posterior cortical atrophy. Neurobiol Aging 2007;28:1051-61 CrossRef Medline

52. Neary D, Snowden JS, Gustafson L, et al. Frontotemporal lobar degeneration: a consensus on clinical diagnostic criteria. Neurology 1998;51:1546-54 CrossRef Medline

53. Shinagawa S, Nakajima S, Plitman E, et al. Psychosis in frontotemporal dementia. J Alzheimers Dis 2014;42:485-99 CrossRef Medline

54. Landqvist Waldö M, Gustafson L, Passant U, et al. Psychotic symptoms in frontotemporal dementia: a diagnostic dilemma? Int Psychogeriatr 2014;27:531-39 CrossRef Medline

55. Mahoney CJ, Beck J, Rohrer JD, et al. Frontotemporal dementia with the C9ORF72 hexanucleotide repeat expansion: clinical, neuroana- 
tomical and neuropathological features. Brain 2012;135(pt 3): 736-50 CrossRef Medline

56. Chan D, Anderson V, Pijnenburg Y, et al. The clinical profile of right temporal lobe atrophy. Brain 2009:132 (pt 5):1287-98 CrossRef Medline

57. Omar R, Sampson EL, Loy CT, et al. Delusions in frontotemporal lobar degeneration. J Neurol 2009;256:600-07 CrossRef Medline

58. Kitagaki H, Mori E, Yamaji S, et al. Frontotemporal dementia and Alzheimer disease: evaluation of cortical atrophy with automated hemispheric surface display generated with MR images. Radiology 1998;208:431-39 CrossRef Medline

59. Looi JCL, Lindberg O, Zandbelt BB, et al. Caudate nucleus volumes in frontotemporal lobar degeneration: differential atrophy in subtypes. AJNR Am J Neuroradiol 2008;29:1537-43 CrossRef Medline

60. Johnson RT, Gibbs CJ. Creutzfeldt-Jakob disease and related transmissible spongiform encephalopathies. N Engl J Med 1998;339: 1994-2004 CrossRef Medline

61. Armstrong RA. Creutzfeldt-Jakob disease and vision. Clin Exp Optom 2006;89:3-9 CrossRef Medline

62. Nozaki I, Hamaguchi T, Noguchi-Shinohara M, et al. The MM2cortical form of sporadic Creutzfeldt-Jakob disease presenting with visual disturbance. Neurology 2006;67:531-33 CrossRef Medline

63. Finkenstaedt M, Szudra A, Zerr I, et al. MR imaging of CreutzfeldtJakob disease. Radiology 1996;199:793-98 CrossRef Medline

64. Kallenberg K, Schulz-Schaeffer WJ, Jastrow U, et al. CreutzfeldtJakob disease: comparative analysis of MR imaging sequences. AJNR Am J Neuroradiol 2006;27:1459-62 Medline

65. Collie DA, Summers DM, Sellar RJ, et al. Diagnosing variant Creutzfeldt-Jakob disease with the pulvinar sign: MR imaging find- ings in 86 neuropathologically confirmed cases. AJNR Am J Neuroradiol 2003;24:1560-69 Medline

66. Walterfang M, Mocellin R, Velakoulis D. Visual hallucinations in consultation-liaison neuropsychiatry. Acta Neuropsychiatrica 2007; 19:330-37 CrossRef

67. Burns A, Gallagley A, Byrne J. Delirium. J Neurol Neurosurg Psychiatry 2004:75:362-67 CrossRef Medline

68. Zuccoli G, Gallucci M, Capellades J, et al. Wernicke encephalopathy: MR findings at clinical presentation in twenty-six alcoholic and nonalcoholic patients. AJNR Am J Neuroradiol 2007;28:1328-31 Medline

69. Velakoulis D, Wood SJ, Wong MT, et al. Hippocampal and amygdala volumes according to psychosis stage and diagnosis: a magnetic resonance imaging study of chronic schizophrenia, first-episode psychosis, and ultra-high-risk individuals. Arch Gen Psychiatry 2006;63: 139-49 CrossRef Medline

70. Black DW, Nasrallah A. Hallucinations and delusions in 1,715 patients with unipolar and bipolar affective disorders. Psychopathology 1989;22:28-34 CrossRef Medline

71. Goodwin DW, Alderson P, Rosenthal R. Clinical significance of hallucinations in psychiatric disorders: a study of $\mathbf{1 1 6}$ hallucinatory patients. Arch Gen Psychiatry 1971;24:76-80 CrossRef Medline

72. Mueser KT, Bellack AS, Brady EU. Hallucinations in schizophrenia. Acta Psychiatr Scand 1990;82:26-29 CrossRef Medline

73. Dauvilliers Y, Billiard M, Montplaisir J. Clinical aspects and pathophysiology of narcolepsy. Clin Neurophysiol 2003;114:2000-17 CrossRef Medline 
7 he authors of "Distinguishing Neuroimaging Features in Patients Presenting with Visual Hallucinations" (T.T. Winton-Brown,

A. Ting, R. Mocellin, D. Velakoulis, and F. Gaillard, AJNR Am J Neuroradiol 2016;37:774-81) neglected to include an author who contributed materially to the paper. M. Walterfang should have been listed fourth in the author order between R. Mocellin and D. Velakoulis.

http://dx.doi.org/10.3174/ajnr.A5389 